\title{
Up-conversion nanomaterial doped with Au nanoparticles with photothermal conversion for multi-modality imaging
}

\author{
Zhangwei ${ }^{1}$, Yanli Lu' ${ }^{1}$, Yang Zang1, Qingyun Xiong ${ }^{1}$ and Jinping Xiong ${ }^{1,3^{*}}$ \\ 1 Beijing Key Laboratory of Electrochemical Process and Technology of Materials, Beijing University of \\ Chemical Technology, Beijing 100029, People's Republic of China \\ 2 State Key Laboratory of Organic-Inorganic Composites, Beijing University of Chemical Technology, Beijing \\ 100029, People's Republic of China \\ 3 College of Ecology and Resources Engineering, Wuyi University, Wuyishan 354300, People's Republic of \\ China \\ * Correspondence: xiongjp@mail.buct.edu.cn
}

\begin{abstract}
In this study, a new method for synthesizing Au-NaYF 4 : $\mathrm{Yb}^{3+} / \mathrm{Er}^{3+}-\mathrm{DSPE}-\mathrm{PEG}_{2 \mathrm{~K}}$ nanocomposites was introduced. Using a hydrothermal method, the synthesized $\mathrm{Yb}^{3+}$ - and $\mathrm{Er}^{3+}$-codoped $\mathrm{NaYF}_{4}$ upconversion luminescent materials and $\mathrm{Au}$ nanoparticles were doped into upconversion nanomaterials and modified with DSPE-PEG $2 \mathrm{k}$ up-conversion nanomaterials. This material is known as Au-UCNPs-DSPE-PEG 2 , it improves both the luminous intensity because of the doped $\mathrm{Au}$ nanoparticles and has low cytotoxicity because of the DSPE-PEG $2 \mathrm{k}$ modified. Exciting UCNPs with a wavelength of $980 \mathrm{~nm}$ near-infrared light will emit light with a wavelength of $520 \mathrm{~nm}$ to further excite gold nanoparticles to convert light energy into heat. Successful synthesized gold nanoparticles was confirmed using transmission electron microscopy (TEM). The morphology of UCNPs was observed using scanning electron microscopy (SEM), and the mapping confirmed the successful doping of Au nanoparticles. Fluorescence spectra were used to compare changes in luminescence intensity before and after doping Au nanoparticles. The cytotoxicity of Au-UCNPs-DSPE$\mathrm{PEG}_{2 \mathrm{~K}}$ was tested via the cell counting kit-8 (CCK-8) method, and its imaging ability was characterized using the Magnetic Resonance Imaging (MRI) and Computed Tomography (CT) method.
\end{abstract}

Keywords: up-conversion; nanomaterials; photothermal conversion; multi-modality imaging

\section{Introduction}

Generally, upconversion rare-earth nanomaterials are used in many fields because of their high fluorescence intensity. Recently, their application in biomedicine has been extensively studied. Many researchers proposed that they can be used in biological imaging because they provide considerable advantage in the fight against major diseases such as cancer [1-3]. However, the common limitation is that upconversion rare-earth nanomaterials have insufficient luminous intensity and are toxic to biological cells; therefore, the modification of structure and surface is necessary. To increase luminous intensity, many researchers proposed doping $\mathrm{Mo}^{3+}, \mathrm{Cu}^{2+}$, and other metal ions in the $\mathrm{NaYF}_{4}: \mathrm{Yb}^{3+} /$ $\mathrm{Er}^{3+}$ unit cell; however, the effect is not significant [4-6]. Other studies proposed doping with Ag, which has a significant effect but Ag has a high light-to-heat conversion efficiency and can cause cell apoptosis without targeting; therefore, Ag cannot be used in biological studies [7,8]. Many researchers proposed developing core-shell structures such as $\mathrm{NaYF}_{4}: \mathrm{Yb}^{3+} / \mathrm{Er}^{3+} @ \mathrm{NaGdF}_{4}: \mathrm{Yb}^{3+}$ and $\mathrm{NaYF}_{4}: \mathrm{Yb}^{3+} / \mathrm{Er}^{3+} @ \mathrm{NaNdF}_{4}: \mathrm{Yb}^{3+} / \mathrm{Tm}^{3+} @ \mathrm{NaGdF}_{4}: \mathrm{Yb}^{3+}$ [9-11]. Alternatively, the material surface is covered with a biocompatible coating such as DSPE-PEG2K and ICG [12-14]. Although these operations can reduce biological toxicity and meet the basic requirements for use in biological cells or animals, these structures will indeed reduce the luminous intensity of upconversion luminescent materials [15-17]. If such a material is used as a contrast agent for CT imaging, the image will be unclear; moreover, the tumor cannot be observed and additional diagnosis and treatment will be 
difficult [18-20]. Therefore, this study proposes a new structural upconversion nanomaterial that has both extremely low cytotoxicity and good luminescence intensity and good targeting that can accurately label tumor cells and can be used for in-vivo imaging and obtain clear tumor images using Micro-CT.

\section{Experimental}

\subsection{Materials}

$\mathrm{Y}_{2} \mathrm{O}_{3}(99.99 \%), \mathrm{Yb}_{2} \mathrm{O}_{3}(99.99 \%), \mathrm{Er}_{2} \mathrm{O}_{3}(99.99 \%)$, nitric acid $(68 \%)$, sodium fluoride (99.99\%), citric acid (99.99\%), cyclohexane (99.5\%), $\mathrm{HAuCl}_{4}(99.99 \%)$, ethylenediaminetetraacetic acid (EDTA, $\geq 99 \%)$, sodium hydroxide $(\geq 98 \%)$ and polyethylene pyrrolidone (PVP, average molecular weight of 1000000-1500000) were purchased from Aladdin. The cell counting kit 8 (CCK-8) assay kit was purchased from BOVOGEN. All chemicals were used as-received without additional purification.

\subsection{Synthesis of nanomaterials}

\subsubsection{Synthesis of Au nanoparticles}

By dropping, $60 \mathrm{~mL}$ of $0.05 \mathrm{~mol} / \mathrm{L}$ of citric acid solution was added to $3 \mathrm{~mL}$ of 0.02 $\mathrm{mol} / \mathrm{L}$ of $\mathrm{HAuCl}_{4}$ to obtain a mixture. Moreover, after $5 \mathrm{~min}$ of continuous stirring, the solution was transferred to a $100 \mathrm{~mL}$ reactor and placed in an oven for the reaction at $180^{\circ} \mathrm{C}$ for $12 \mathrm{~h}$. The reaction was then cooled to room temperature, washed, and centrifuged to obtain solid Au nanoparticles, and then added to $10 \mathrm{~mL}$ of deionized water and PVP, and then placed in a test tube to prepare the sol for use.

\subsubsection{Synthesis of Au-UCNPs}

$\mathrm{RE}_{2} \mathrm{O}_{3}(\mathrm{RE}=\mathrm{Y}, \mathrm{Yb}, \mathrm{Er})$ was heated to achieve complete dissolution in excess nitric acid and then transferred to a vacuum system for evaporation to obtain a solid $\mathrm{RE}\left(\mathrm{NO}_{3}\right)_{3}$, which was then dissolved in deionized water and recrystallized twice. A certain amount of solid $\mathrm{RE}\left(\mathrm{NO}_{3}\right)_{3}$ was dissolved in deionized water, and EDTA (molar ratio of EDTA: $\mathrm{RE}\left(\mathrm{NO}_{3}\right)_{3}=1: 1$ ) was added and stirred at $600 \mathrm{rpm}$ for $1 \mathrm{~h}$, the mixture was then weighed and dissolved in sodium fluoride in deionized water by ultrasound, and then the solution was added and stirred at $600 \mathrm{rpm}$ for $1 \mathrm{~h}$. Finally, the $\mathrm{pH}$ value was adjusted to 5.5 with $\mathrm{NaOH}$ and add $10 \mathrm{ml}$ of sliver, and then place it in a hydrothermal kettle to react at $190^{\circ} \mathrm{C}$ for $24 \mathrm{~h}$. The reaction products were cooled, centrifuged, and washed twice with ethanol/deionized water $(1: 1 \mathrm{v} / \mathrm{v})$, and dried in vacuum at $80^{\circ} \mathrm{C}$ for $3 \mathrm{~h}$. The resultant powder is dispersed in cyclohexane for later use.

\subsubsection{DSPE-PEG2K modified Au-UCNPs}

First, $6 \mathrm{~mL}$ of Au-UCNPs $(0.4 \mathrm{mmol})$ dispersed in chloroform were mixed with 20 $\mathrm{mL}$ of DSPE-PEG $2 \mathrm{~K}(100 \mathrm{mg})$ chloroform solution in $5 \mathrm{~mL}$ open glass bottles. After heating at $75^{\circ} \mathrm{C}$ for $5 \mathrm{~min}$ to remove the chloroform, adding $24-\mathrm{mL}$ water to complete the ultrasonic dispersion, stirring at $75^{\circ} \mathrm{C}$ for $10 \mathrm{~min}$, cool to room temperature, centrifuged at $18000 \mathrm{rpm}$ for $8 \mathrm{~min}$ to take the precipitate, and adding $1 \mathrm{~mL}$ of normal saline to disperse, large particles were removed by centrifugation at $5000 \mathrm{rpm}$ for $5 \mathrm{~min}$ and then dried by a blast at $75{ }^{\circ} \mathrm{C}$.

\subsection{Characterization}

Transmission electron microscopy (TEM) measurements were performed on a JEOL 2011 microscope operating at $200 \mathrm{kV}$. All samples were first dispersed in ethanol and then collected using a $\mathrm{Cu}$ grid covered with a carbon film for measurement. To determine the elemental composition of the samples, energy-dispersive X-ray spectroscopy (EDS) of the samples was performed on a JEOL 2010 EDS instrument using high-resolution transmission electron microscopy (HRTEM) measurements. Inductively coupled plasma-atomic emission spectrometry (ICPAES) was performed using a Perkin Elmer 7300DV apparatus. Scanning electron microscopy (SEM) images were obtained using a Philips XL30 electron 
microscope operating at $20 \mathrm{kV}$. Before this characterization, a Au film was sprayed on the sample. The upconversion luminescence spectrum was obtained using a spectrum analyzer (ANDO AQ6317, Japan). The sample was placed in a 1.0-cm path length support, which was excited using a 980-nm CW semiconductor diode laser (Pmax $800 \mathrm{~mW}$, $1000 \mathrm{~mA}$ ). The upconversion luminescence spectrum was obtained by the spectrophotometer using a multimode fiber having a core diameter of $0.6 \mathrm{~mm}$. The distance between the top of the fiber and sample is $\sim 2 \mathrm{~mm}$.

\subsection{Biological test}

\subsubsection{CCK-8 assay for cytotoxicity}

The culture medium in the flask was sucked out, washed with PBS, and then $0.25 \%$ of trypsin was added to digest cells after culturing HeLa cells in the logarithmic growth phase. After the removal of trypsin, the DMEM medium containing $10 \%$ fetal bovine serum was added to blow the cells, which were then transferred to the sampling tank and blown well. Subsequently, $100 \mu \mathrm{L}$ cells were injected into a 96-well plate $\left(1 \times 10^{4}\right.$ cells/well $)$ and incubated for $24 \mathrm{~h}$ in a constant temperature incubator at $37^{\circ} \mathrm{C}\left(5 \% \mathrm{CO}_{2}\right)$. The cells were incubated for $1.5 \mathrm{~h}$ in an incubator at $37^{\circ} \mathrm{C}$ with $5 \% \mathrm{CO}_{2}$ in accordance with concentrations of 200, 300, 400, 500, and $600 \mu \mathrm{g} / \mathrm{mL}$. The culture medium was blotted out, PBS was rinsed twice, the culture medium was replaced in the 96-well plates with $100 \mu \mathrm{L}$ of fresh DMEM containing 10\% fetal bovine serum, and then $10 \mu \mathrm{L}$ of CCK-8 solution was added to each well. The absorbance of each well at $450 \mathrm{~nm}$ was measured using a microplate reader after $2 \mathrm{~h}$ of culturing in the incubator. The cell survival rate calculation formula is as follows:

Cell survival rate $(\%)=($ A sample $) /($ A control $) \times 100 \%$

\subsubsection{Establishment of animal tumor model}

A BALB/c female white mouse with SPF grade weighing $18 \mathrm{~g}$ was depilated, and Hela cells growing in log phase were subcutaneously injected into the upper right hind leg of the mouse to construct a mouse Hela subcutaneous tumor growth model.

\subsubsection{MRI and CT imaging of mice}

Use isoflurane to anaesthetize the mice throughout the entire process, place them in animal MRI machine (NM42-040H-I), which with a magnetic field strength of 1T, and perform a tomographic scan of the tumor site on mice whose tumors grow to $100 \mathrm{~mm}^{3}$ to obtain pre images. Then $200 \mathrm{ug} / \mathrm{ml}$ of Au-UCNPs-DESP-PEG2K solution was injected, and images were collected again. Using the same method, place the mouse on a SPECT/CT (tube current: $615 \mu \mathrm{A}$, tube voltage: $55 \mathrm{kV}$ ) animal bed, perform pre image acquisition of full-angle CT imaging in precise mode, and then acquire the tomographic image of the tumor site again after the injection of 200ug/ml of Au-UCNPs-DESP-PEG2K solution.

\subsubsection{H\&E stained sections}

Take one mouse from the control group and one from the experimental group, take out their organs (heart, liver, spleen, lung, kidney) and tumor sites, and soak them in a $10 \%$ formalin buffer solution for 24 hours. Carry out H\&E pathological staining of longitudinal section, and observe the influence of A on them using electron microscope.

\section{Results and Discussion}

The TEM images of Au nanoparticles (Fig. 1) prepared using the hydrothermal method show that they are spherical and have an average diameter of $5 \mathrm{~nm}$. 
(a)



(b)

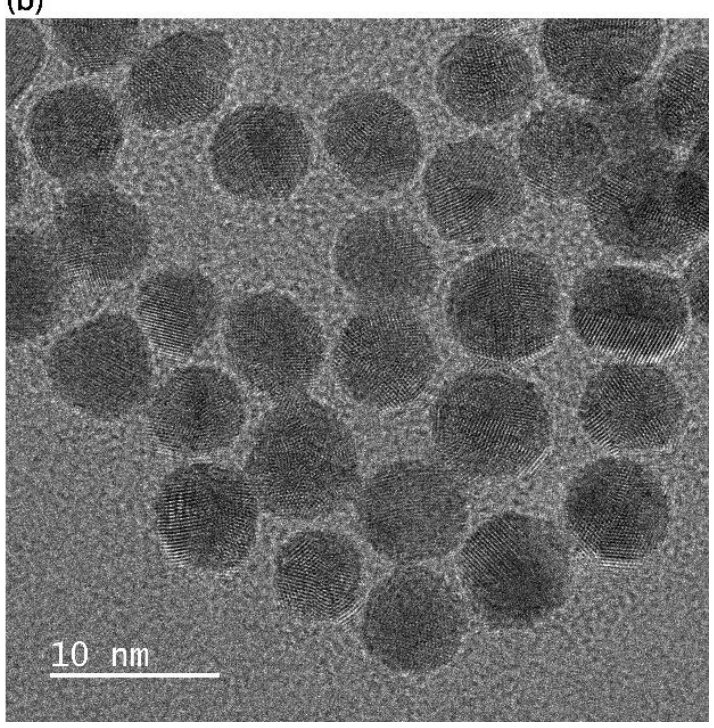

Figure 1. (a): TEM image of Au nanoparticles and (b): lattice of (a).

TEM images show the morphology of Au-UCNPs (Fig. 2). They are rod structures with a length of $50 \mathrm{~nm}-100 \mathrm{~nm}$ and narrow ends. The reason for this phenomenon is that during the nucleation and growth of the nanoparticles by coprecipitation-hydrothermal method, the temperature controls its width and shape, and the time determines its length. When the temperature starts to drop, the two ends of the nanorod begin to shrink with the decrease of temperature, and finally show the phenomenon of narrowing at both ends. The successful doping of Au into nanoparticles was proved by energy spectrum (Fig. 3).

(a)

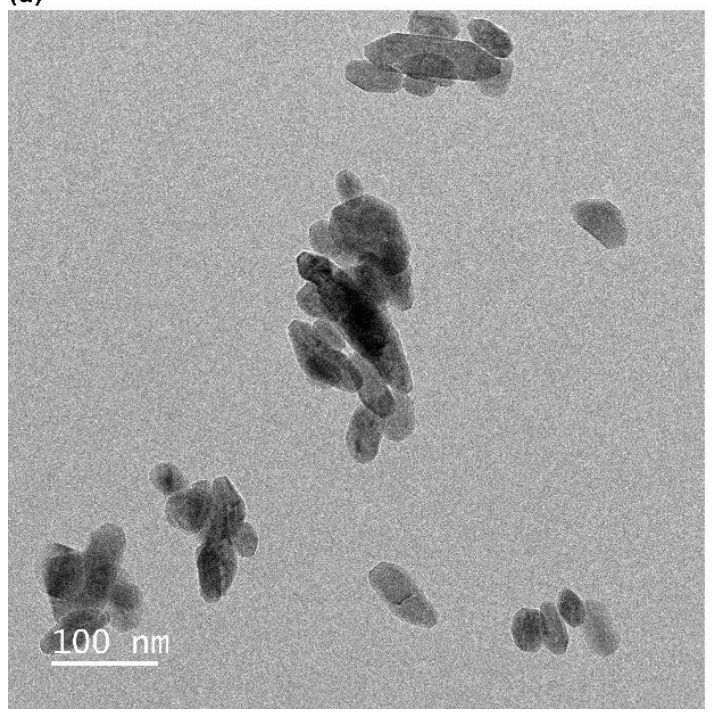

(b)

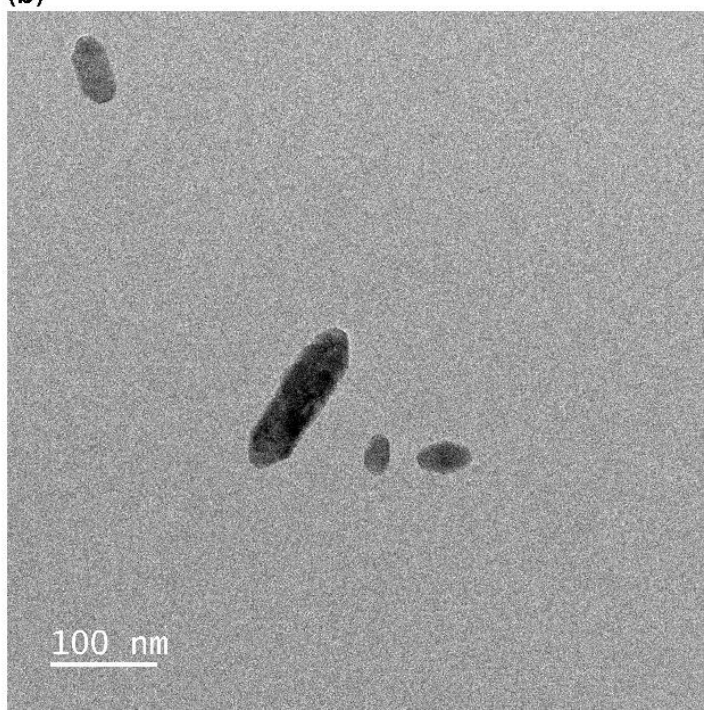

Figure 2. TEM image of Au-UCNPs. 


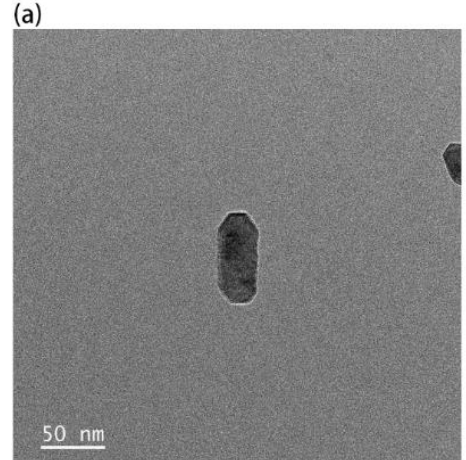

(d)

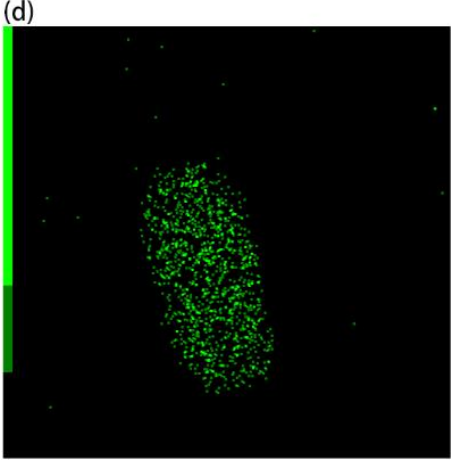

(b)

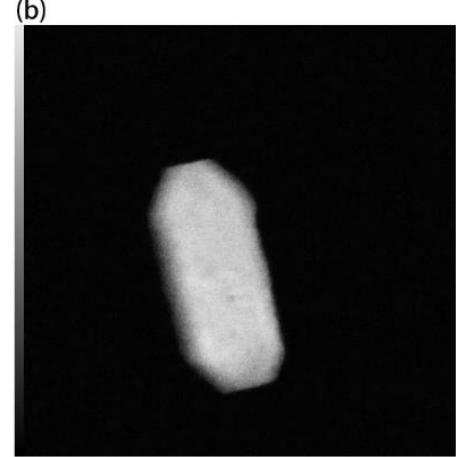

(e)

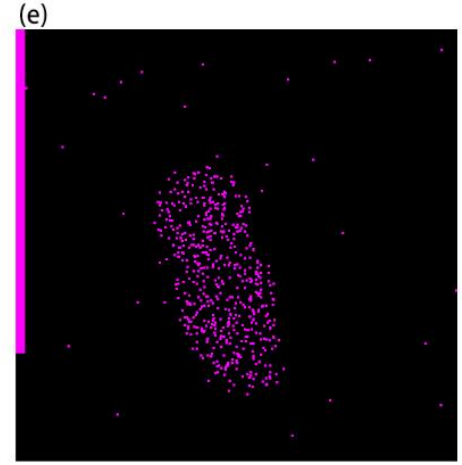

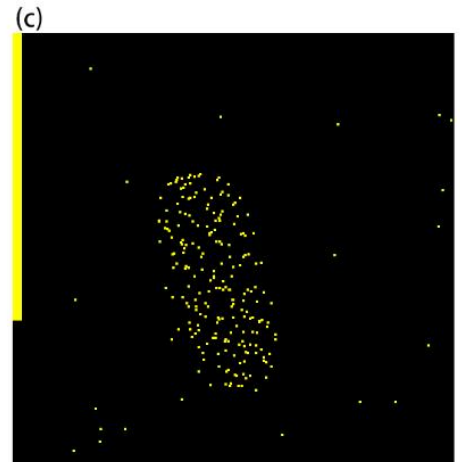

(f)

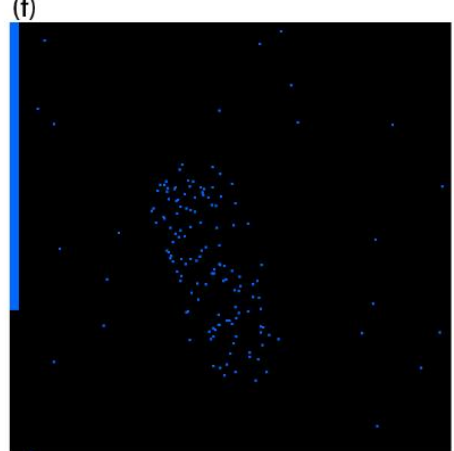

Figure 3. (a): TEM image of Au-UCNPs, (b): energy of (a), (c-f):mapping of (b).

Both UCNPs and Au-UCNPs were prepared in $0.2 \mathrm{M}$ solutions and their luminescence intensity (Fig. 4) at a wavelength of $980 \mathrm{~nm}$ was tested. The results demonstrated that the luminescence intensity increased by $\sim 2.5$ times after doping with Au.

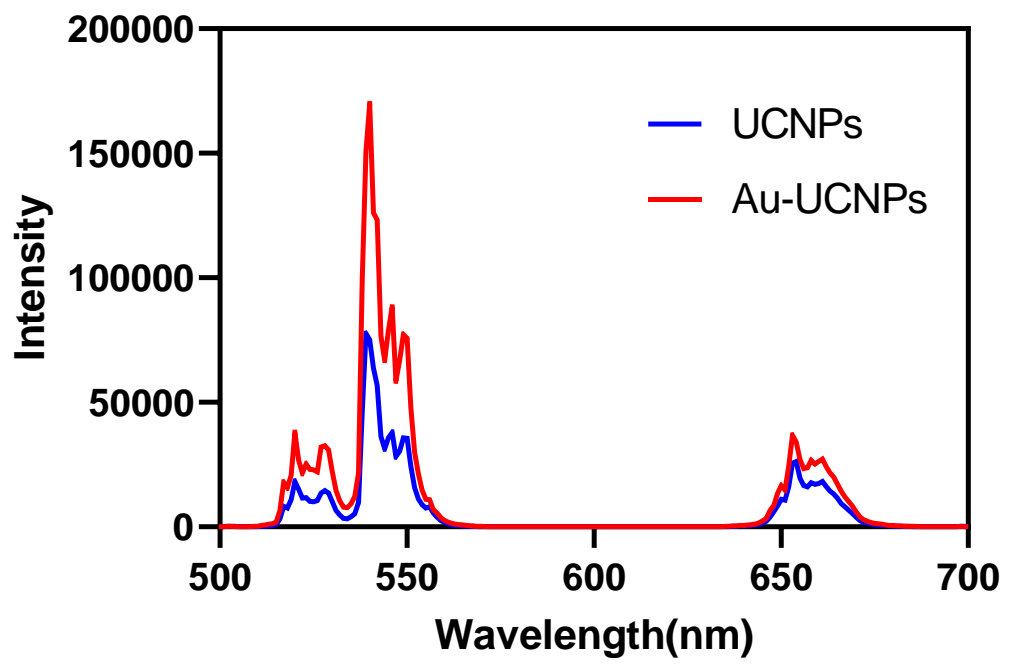

Figure 4. Luminescent intensity of UCNPs and Au-UCNPs.

The modified rare-earth nanomaterials were dispersed in normal saline to prepare different concentrations, after which HeLa cells were cultured for $4 \mathrm{~h}$ and their activity was tested (Fig. 5). It has been suggested that when the concentration is less than 400 $\mathrm{ug} / \mathrm{mL}$, the cell survival rate is higher than $89 \%$. Especially at a concentration of 200 $\mathrm{ug} / \mathrm{mL}$, the cell survival rate was more than $99 \%$. Combined with Fig. 4 , the luminescence intensity of rare earth, $200 \mathrm{ug} / \mathrm{mL}$ concentration of rare-earth nanomaterials not only have sufficient safety but also have a high luminous intensity. When the concentration of rareearth ions is as high as $500 \mathrm{ug} / \mathrm{mL}$ or even $600 \mathrm{ug} / \mathrm{mL}$, the cell survival rate is still higher than $80 \%$. However, no matter how low the concentration of this material is without being 
modified by DSPE-PEG2K, there is always high cytotoxicity. If such material is used for animal experiments, it will cause serious damage to other animal tissues, so the surface must be modified.

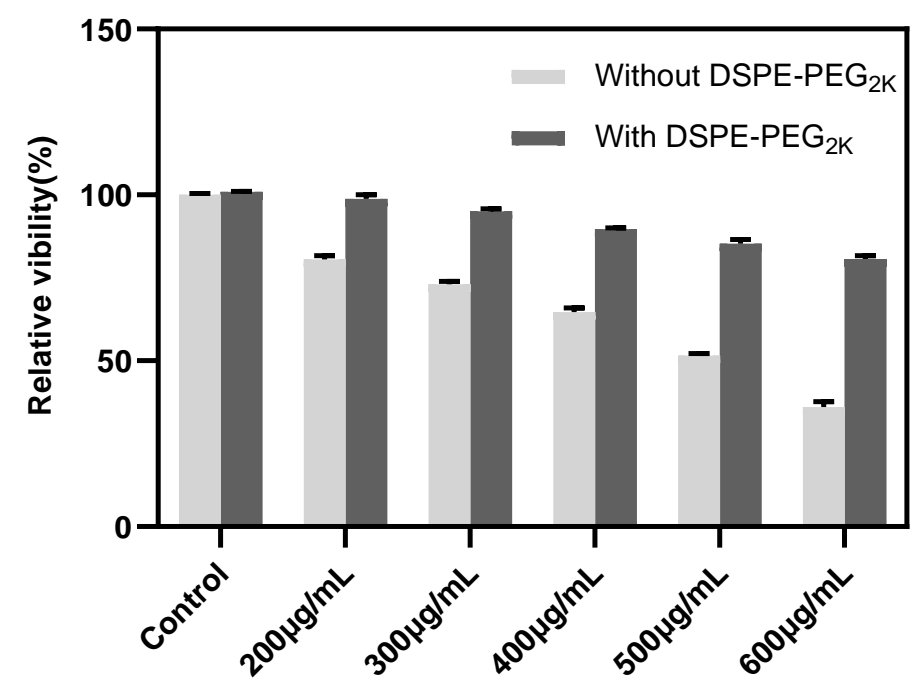

Figure 5. Cytotoxicity of different concentrations of Au-UCNPs and DSPE-PEG2K modified AuUCNPs.

A $200 \mu \mathrm{g} / \mathrm{mL}$ concentration of Au-UCNPs-DSPE-PEG2K was intratumorally injected in the tumor necrosis area, the enhanced MRI signal can be clearly observed in the injection area (Fig. 6).

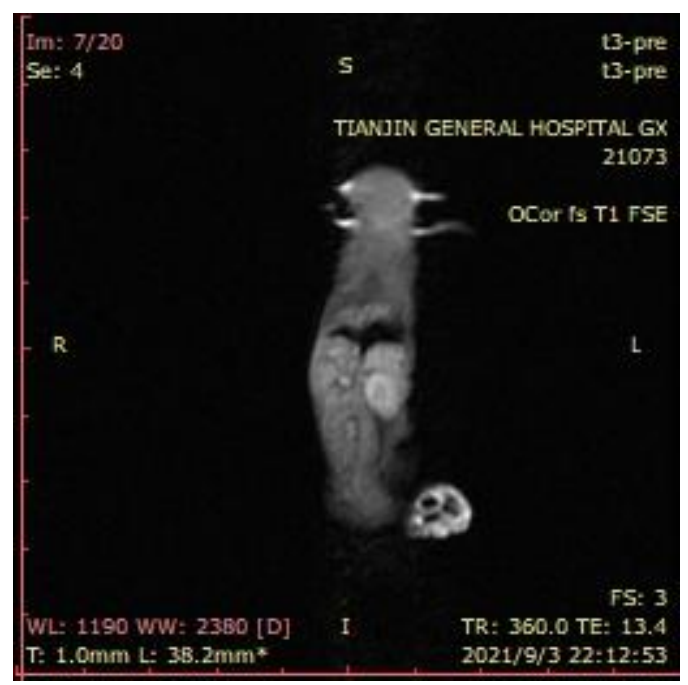

Figure 6. T1-weighted MR images of a tumor-bearing Balb/c mouse after injection $200 \mu \mathrm{g} / \mathrm{mL}$ of AuUCNPs-DSPE-PEG 2 .

A $200 \mu \mathrm{g} / \mathrm{mL}$ concentration of Au-UCNPs-DSPE-PEG2K was intratumorally injected in the mice. Fig. 7(c) shows that the tumor site of the mouse before injection has no signal under Micro-CT imaging; furthermore, 30 min after the injection of Au-UCNPs-DSPE$\mathrm{PEG}_{2 \mathrm{~K}}$ (Fig. 7 d), the tumor site of the mouse shows a CT Signal. 
(a)

\section{Pre}

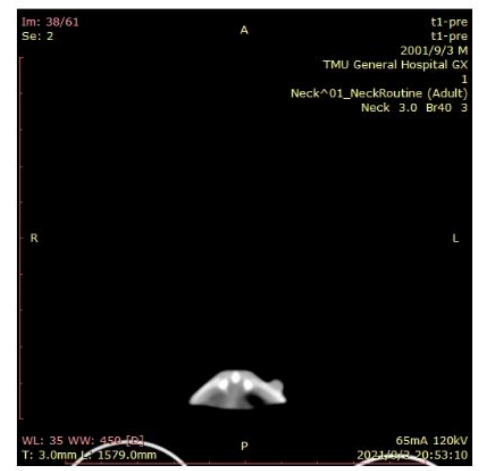

(b)

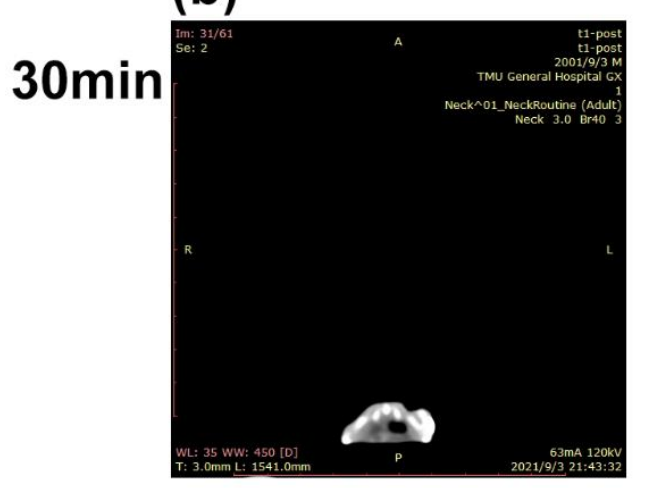

(c)

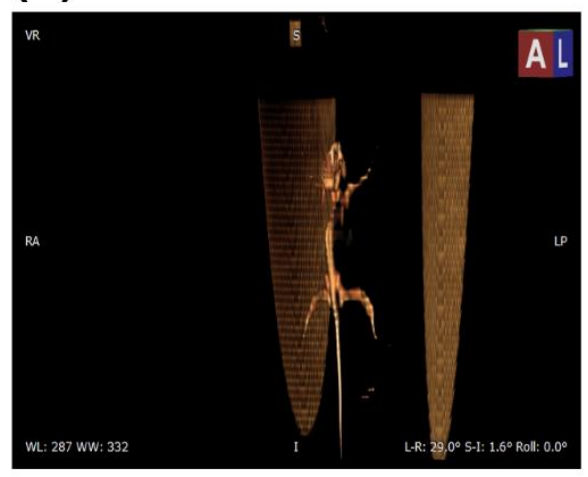

(d)

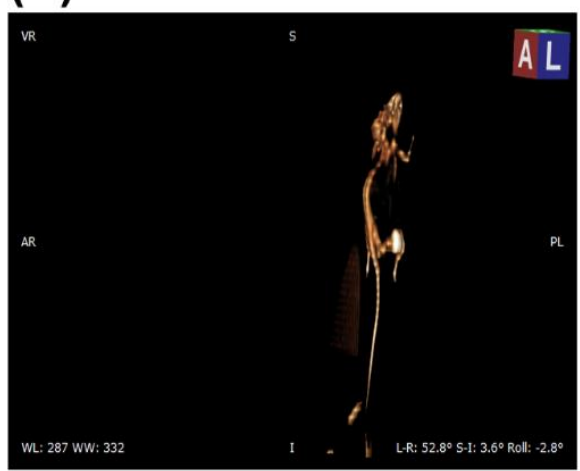

Figure 7. Micro-CT images before(a) and after(b) intratumor injection of Au-UCNPs-DSPE-PEG2K in Balb/c mice, (c),(d) is the 3D model of (a) and (b) respectively.

By comparing the $\mathrm{H} \& \mathrm{E}$ staining diagram of the longitudinal section of each organ of mice before and after injection of Au-UCNPs-DSPE-PEG2K (Fig. 8), it can be seen that the cells of each organ were not damaged or inflamed after injection of Au-UCNPs-DSPEPEG2K. 


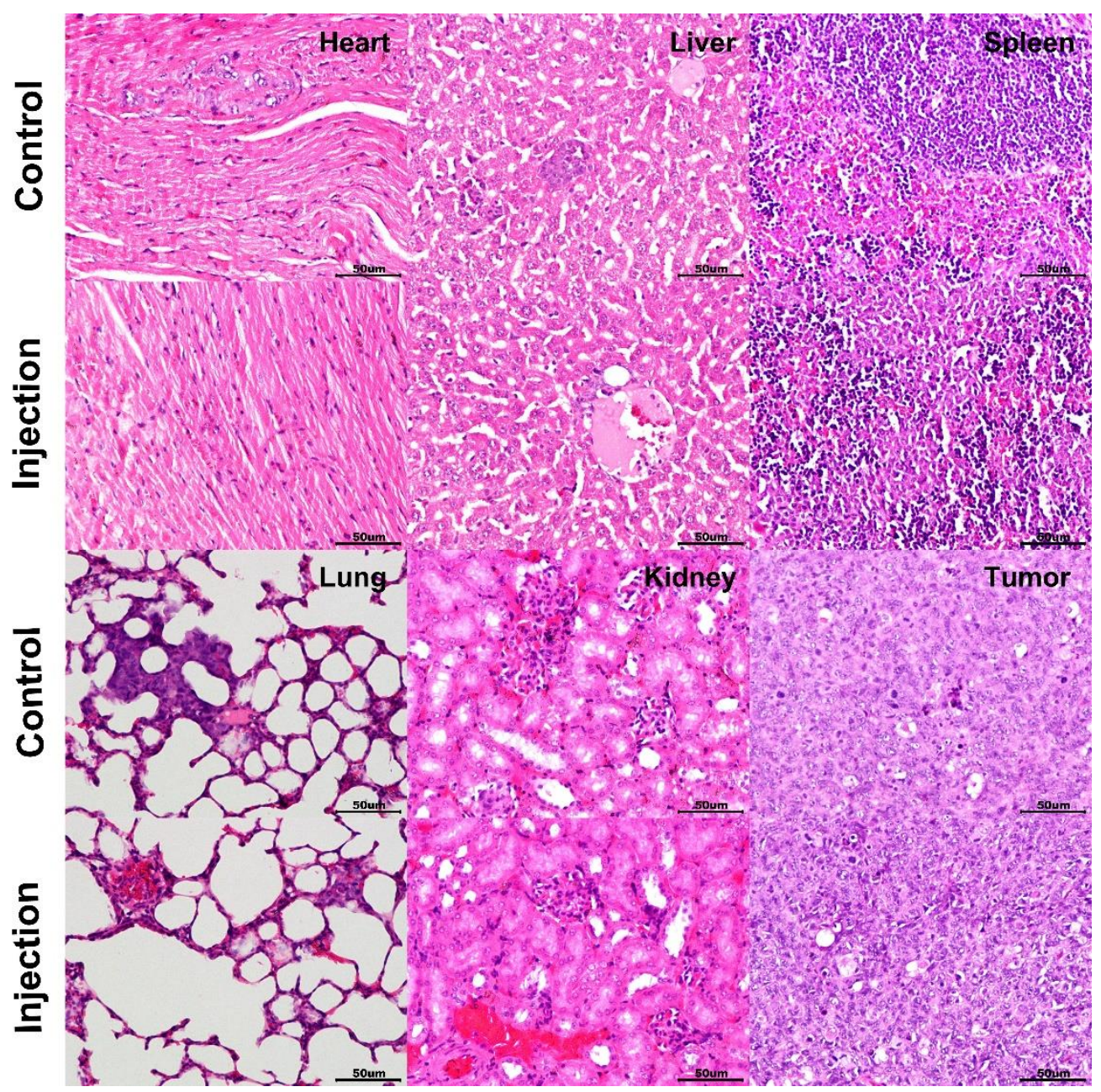

Figure 8. Comparison of H \& E staining sections of various organs (heart, liver, spleen, lung, kidney) and tumors of mice before and after injection.



Figure 9. Temperature rise-drop curve of Au-UCNPs-DSPE-PEG $2 \mathrm{~K}$ with different concentrations irradiated by $980 \mathrm{~nm}$ near-infrared light.

In addition to the imaging function, Au-UCNPs-DSPE-PEG $2 \mathrm{~K}_{\text {has }}$ a certain photothermal conversion efficiency, and its temperature rise curve (Fig. 9) meets the requirements of photothermal treatment. In the future, Au-UCNPs-DSPE-PEG 2 m may be used as a reagent for photothermal treatment of cancer. 


\section{Conclusions}

The doped Au nanoparticles increase the luminous intensity of UCNPs; it greatly improves the luminous intensity of up-conversion nano-materials and has extremely low cytotoxicity. These nanoparticles can be used as an excellent biomedical material. Second, compared with the traditional medical imaging, tumor images can be observed in the multi-modality imaging system. The images can play an important role in future treatment of tumor, thus providing complete and clear images for diagnosing and treating complex cancers such as blood metastasis. Finally, the extremely high luminous intensity of this material is primarily attributed to Au nanoparticles, which have good photothermal conversion efficiency. In future, this material could be used along with photothermal therapy (PTT), which is used to complete the cancer treatment and diagnosis.

Author Contributions: Conceptualization, W.Z. and Y.Z.; methodology, W.Z.; software, Y.L.; validation, W.Z., Y.Z., and Y.L.; formal analysis, Y.L.; resources, Q.X.; data curation, Q.X. and Y.L.; writing-original draft preparation, W.Z.; writing - review and editing, J.X.; supervision, J.X. All authors read and agreed to the published version of the manuscript.

Funding: This research received no external funding.

Institutional Review Board Statement: Not applicable.

Informed Consent Statement: Not applicable.

Data Availability Statement: No new data were created or analyzed in this study. Data sharing is not applicable to this article.

Acknowledgments: The authors also would like to thank the Shiyanjia Lab(www.shiyanjia.com , 8 2021) for animal experiment.

Conflicts of Interest: The authors declare no conflict of interest.

\section{References}

1. A.M. Alattar, R.A. Mohammed, M.J. Alwazzan, W.A.A. Twej, Dispersion of pure silica xerogel vs NaYF4- xerogel nanomaterials in silica aerogel and their effect on the optical and structural properties, Opt. Mater. 118 (2021) 111274. https://doi.org/10.1016/j.optmat.2021.111274.

2. A.A. Ansari, A.K. Parchur, N.D. Thorat, G.Y. Chen, New advances in pre-clinical diagnostic imaging perspectives of functionalized upconversion nanoparticle-based nanomedicine, Coordin. Chem. Rev. $440 \quad$ (2021) 213971. https://doi.org/10.1016/j.ccr.2021.213971.

3. N. Chowdhury, N. Riesen, H. Riesen, Yb3+ and Er3+ codoped BaLiF3 nanocrystals for x-ray dosimetry and imaging by upconversion luminescence, ACS Appl. Nano Mater. 4 (2021) 6659-6667. https://doi.org/10.1021/acsanm.1c00600.

4. A. Cordonnier, D. Boyer, S. Besse, R. Valleix, R. Mahiou, M. Quintana, A. Briat, M. Benbakkar, F. Penault-Llorca, A. MaisonialBesset, B. Maunit, S. Tarrit, M. Vivier, T. Witkowski, L. Mazuel, F. Degoul, E. Miot-Noirault, J.M. Chezal, Synthesis and in vitro preliminary evaluation of prostate-specific membrane antigen targeted upconversion nanoparticles as a first step towards radio/fluorescence-guided surgery of prostate cancer, J. Mater. Chem. B (2021). https://doi.org/10.1039/d1tb00777g.

5. L. Dong, C.Y. Zhang, L. Yan, B.B. Zhang, H. Chen, X.H. Mi, Z.K. Fu, Z.L. Zhang, H.R. Zheng, Quantifying plasmon resonance and interband transition contributions in photocatalysis of gold nanoparticle*, Chinese Phys. B 30 (2021) 077301. https://doi.org/10.1088/1674-1056/abfa0c.

6. Z.H. Feng, L. Lin, Z.Z. Wang, Z.Q. Zheng, Highly efficient and wide range low temperature sensing of upconversion luminescence of NaYF4: Er3+ nanoparticles: Effects of concentration of active or sensitive ions, excitation power and particle size on temperature sensing sensitivity, Opt. Commun. 491 (2021), 126942. https://doi.org/10.1016/j.optcom.2021.126942.

7. L. Giordano, M.F. Nunes, V.N.C. Teixeira, L.C.V. Rodrigues, Green synthesis of upconverting NaYF4 and NaGdF4 materials and energy levels determination, J. Braz. Chem. Soc. 32 (2021) 1552-1558. https://doi.org/10.21577/0103-5053.20210052.

8. J.M. Jiang, H.H. Ren, F.H. Huang, L. Wang, J.L. Zhang, Refine the crystallinity of upconversion nanoparticles for NIR-enhanced photocatalysis, Crystengcomm. (2021). https://doi.org/10.1039/D1CE00550B.

9. C.M.S. Jones, D. Biner, S. Misopoulos, K.W. Kramer, J. Marques-Hueso, Optimized photoluminescence quantum yield in upconversion composites considering the scattering, inner-filter effects, thickness, self-absorption, and temperature, Sci. Rep-Uk 11 (2021) 13910. https://doi.org/10.1038/s41598-021-93400-8.

10. H. Zong, X.J. Mu, M.T. Sun, Physical principle and advances in plasmon-enhanced upconversion luminescence, Appl. Mater. Today 15 (2019) 43-57. https://doi.org/10.1016/j.apmt.2018.12.015.

11. Y.B. Wang, W.X. Xu, L. Lei, L. Chen, R.G. Ye, S.Q. Xu, Photoluminescent NaGdF4@NaYF4:Ce/Tb inert-core/active-shell nanoparticles for selective and ultra-sensitive Cu2+ions sensing, J. Lumin. 235 (2021) 118024 . https://doi.org/10.1016/j.jlumin.2021.118024. 
12. F. Lu, T. Zhao, X.J. Sun, Z.Q. Wang, Q.L. Fan, W. Huang, Rare-earth doped nanoparticles with narrow NIR-II emission for optical imaging with reduced autofluorescence, Chem. Res. Chinese U 37 (2021) 943-950. https://doi.org/10.1007/s40242-0211172-9.

13. M.K. Mahata, R. De, K.T. Lee, Near-infrared-triggered upconverting nanoparticles for biomedicine applications, Biomedicines 9 (2021) 756. https://doi.org/10.3390/biomedicines9070756.

14. G. Murali, S.V.P. Vattikuti, Y.K. Kshetri, H. Lee, J.K.R. Modigunta, C.S. Reddy, S. Park, S. Lee, B. Poornaprakash, H. Lee, Y.H. Park, J. Lee, S.Y. Park, I. In, Near-infrared-activated Z-scheme NaYF4:Yb/Tm@Ag3PO4/Ag@g-C3N4 photocatalyst for enhanced H2 evolution under simulated solar light irradiation, Chem. Eng. J. 421 (2021) 129687. https://doi.org/10.1016/j.cej.2021.129687.

15. S.S. Panikar, G. Ramirez-Garcia, N. Banu, A.A. Vallejo-Cardona, P. Lugo-Fabres, T.A. Camacho-Villegas, P. Salas, E. de la Rosa, Ligand-targeted theranostic liposomes combining methylene blue attached upconversion nanoparticles for NIR activated bioimaging and photodynamic therapy against HER-2 positive breast cancer, J. Lumin. 237 (2021) 118143. https://doi.org/10.1016/j.jlumin.2021.118143.

16. Y.H. Tai, Y. Zhang, J.L. Sun, F.Y. Liu, H.R. Tian, Q.F. Liu, C.H. Li, Y2O3:Yb3+, Tm3+/ZnO composite with a heterojunction structure and upconversion function for the photocatalytic degradation of organic dyes, RSC Adv. 11 (2021) $24044-24053$. https://doi.org/10.1039/D1RA03066C.

17. Y. Tian, Q.H. Liu, E. Fei, R.G. Ye, S.T. Chen, J.J. Zhang, S.Q. Xu, Structural evolution, crystallization behaviour and mid-infrared emission properties in $\mathrm{Yb} /$ Ho codoped oxyfluoride germanosilicate glass ceramics with varied Si/Ge ratio, Infrared Phys. Techn. 116 (2021) 103741. https://doi.org/10.1016/j.infrared.2021.103741.

18. R.A. Puebla, N.P. Perez, L. Guerrini, SERS-fluorescent encoded particles as dual-mode optical probes, Appl. Mater. Today 13 (2018) 1-14. https://doi.org/10.1016/j.apmt.2018.07.007.

19. J.Y. Xiong, G. Li, J. Zhang, D.S. Li, E.Y.B. Pun, H. Lin, Fluorescence regulation derived from Eu3+ in miscible-order fluoridephosphate blocky phosphor, Nanotechnology 32 (2021) 435705. https://doi.org/10.1088/1361-6528/ac15c7.

20. Y.H. Zhang, X.H. Zhu, J. Zhang, Y.H. Wu, J.L. Liu, Y. Zhang, Synergistic upconversion photodynamic and photothermal therapy under cold near-infrared excitation, J. Colloid. Interf. Sci. 600 (2021) 513-529. https://doi.org/10.1016/j.jcis.2021.05.017. 